\title{
Vervet Monkey Alarm Calls: Setting the Historical Context
}

\author{
Charles T. Snowdon
}

\author{
Department of Psychology, University of Wisconsin, Madison \\ *Corresponding author (Email: snowdon@wisc.edu)
}

Citation - Snowdon, C. T. (2020). Vervet monkey alarm calls: Setting the historical context. Animal Behavior and Cognition, 7(2), 87-94. doi: https://doi.org/10.26451/abc.07.02.02.2020

\begin{abstract}
I review the historical context in which the vervet alarm call papers first appeared, showing that animal behavior researchers at the time were studying a wide array of cognitive abilities in primate communication. I then review how the initial study on vervet alarms has led to research on referential alarm calls in other primates as well as in non-primate species. I briefly review work on food-related calling as another type of referential signal. Overall, the vervet alarm papers have stimulated great interest in the cognitive complexity of animal signals, but, strikingly, it has been difficult to find clear evidence of predator specific alarms in more than a small number of other species. Future research should look at how motivation, emotional and cognitive components are included in animal calls, as well as study how animals respond flexibly to different social or environmental in their communication.
\end{abstract}

Keywords - Referential signals, Alarm calls, Food-related calls, Vocal communication, Context, Cognition

In 1980, Seyfarth, Cheney, and Marler (1980a, b) published two of the most influential papers on animal communication and on animal behavior more generally. The Science paper has had more than 1,360 citations and the more elaborated paper in Animal Behaviour nearly 1,000 citations (Google Scholar, Nov. 29, 2019). These papers have had a significant influence on how we view cognition in nonhuman primates and have been important to theories of language evolution. By illustrating that nonhuman primates can use calls referentially and not just as emotional signals, Seyfarth et al. (1980a, b) added important findings to our understanding of the cognitive aspects of communication. However, this work did not appear in a vacuum. In this paper, I will first describe the historical context of cognitive approaches to animal communication looking first at other areas where cognitive aspects of communication were being studied at the same time, and second, at the context and subsequent progress of research on referential signals.

\section{Context of Animal Cognition and Communication}

Prior to the influential papers by Seyfarth et al. (1980a b), the field of psychology was undergoing a rejection of the behaviorism (the theory that behavior can be explained in terms of conditioned and unconditioned reflexes without recourse to thoughts and feelings) that had dominated the first half of the $20^{\text {th }}$ century. The publication of Ulrich Neisser's Cognitive Psychology (1967), which emphasized the importance of thoughts and other mental processes, was a landmark with Neisser often called the "father of cognitive psychology." Given the influence of cognitive psychology on the research paradigm with humans, similar research on nonhuman animals would soon follow. Donald Griffin published his 
controversial book, The Question of Animal Awareness in 1976, where he argued that mental states were equally important to nonhuman species as well.

About the same time, many researchers began to look for and study examples of cognitive complexity in nonhuman primate communication systems. One of the earliest research areas was the description of subtle variants in communication signals. It had generally been thought that nonhuman animals had limited repertoires (Moynihan, 1970; Smith, 1969), but beginning in the mid-1970's, researchers were discovering that what were previously thought to be unitary call strictures had subtle variants that corresponded to different social and environmental contexts. For example, Green (1975) described seven different types of "coo" vocalizations given by Japanese macaques (Macaca fuscata) in specific social interactions. One type of coo was from dominants to subordinates, another from subordinates to dominants. Another type was given by estrous females and another by males separated from the group and still another by mothers to infants. Thus, Japanese macaques had larger vocal repertoires than previously thought and subtle variations in calls were used in distinctive social contexts. Lillehei and Snowdon (1978) found that stump-tail macaque (Macaca arctoides) infants gave two different versions of coos, structurally similar to those described by Green (1975), one when infants were active on their own; another when seeking contact with the mother.

In the same year, Pola and Snowdon (1975) described four types of trill variants in calls of pygmy marmosets (Cebuella pygmaea). Two of these types: Closed Mouth and Open Mouth Trills occurred in contexts of calm versus agonistic behavior, respectively, but two other distinct trill types, Quiet Trills and J-calls occurred in the same context as the Closed Mouth Trills (at least in captive animals). Cleveland and Snowdon (1982) described eight variations of "chirp" calls in cotton-top tamarins (Saguinus oedipus) with each variant having a specific context: mild alarm, strong alarm, response to neighboring group, approach to food, leaving food, calm contact call, etc. Thus, primate vocalizations were more subtle and complex than previously thought.

One might interpret these call subtleties as constructs of the researchers who described them rather than of being direct use to the animals themselves. However, playback and conditioning studies have shown that many of these distinctions were important to the animals as well. Using operant conditioning methods, Zoloth et al. (1979) presented several exemplars of smooth early high and late high coos ("early" and "late" referring to when the peak frequency of the call was reached) to Japanese macaques as well as to some other monkey species. Two conditioning paradigms were used: animals were asked to discriminate based on the call type or based on the average pitch of the calls regardless of call type. Japanese macaques could discriminate easily between smooth early high and smooth late high coos when compared with other species, but the other species could more readily discriminate calls than Japanese macaques when reward was based on pitch. Petersen et al. (1984) showed that the discrimination of these calls was lateralized with a right ear/left hemisphere advantage in processing coo calls by Japanese macaques that other species did not have, paralleling human language processing. May, Moody and Stebbins (1989) used synthetic versions of coo calls and found that Japanese macaques showed categorical perception of the two coo types. Thus, there appeared to be clear evidence for at least some Japanese macaque coos of species-specific perceptual processing and relevance that paralleled those of human speech perception.

In pygmy marmosets, Snowdon and Pola (1978) presented synthetic trills on a continuum between Closed Mouth and Open Mouth Trills and also found evidence for categorical responding. Bauers and Snowdon (1990) played back the two acoustically most similar chirp vocalizations of cottontop tamarins and found that tamarins discriminated readily between the two types of calls in terms of the behavioral responses that each call elicited. Thus, the increased repertoire size of monkeys appears to be real. The subtle differences are perceived by conspecifics and lead to appropriate behavioral responses.

The three trills of very different structure that appeared in similar contexts in captive pygmy marmosets still needed to be explained. Based on acoustic structure and principles of sound localization, it was predicted that Quiet Trills should be cryptic and used when animals were close to each other, whereas the J-calls with a broad frequency range and several interrupted notes should be locatable over longer distances. Field studies in Peru by Snowdon and Hodun (1981) and in Ecuador by de la Torre and 
Snowdon (2002) showed that calls were used selectively when animals were at different distances from each other. Thus, the cryptic Quiet Trills were used when animals were close together, the Closed Mouth Trills when they were at moderate distances from each other and the J-calls at further distances. Pygmy marmosets must be monitoring their social environment closely and altering the structure of their calls according to their perceived distance from other group members.

Other research showed that there were syntactic structures in nonhuman primate calls. Robinson (1979) studying titi monkeys (Callicebus moloch, now Plecturocebus moloch) reported that calls were combined to form phrases and phrases combined to make longer sequences. There appeared to be a fixed sequence of call types, and when Robinson presented call sequences in a different order than normal, the monkeys showed "disturbance reactions". The study did not distinguish between whether animals reacted simply to the novelty of the altered stimuli or because they understood that syntactic structure had been violated. Cleveland and Snowdon (1982) described phrases made of several notes in cotton-top tamarins. These appeared to follow a fixed sequence with short notes preceding longer notes and pitch increasing with successive calls. A clever study in cotton-top tamarins involving interrupting long call sequences with white noise (Miller et al., 2003) showed that calls were interrupted after the completion of the current call unit rather than after the full sequence. This suggests that long call sequences are organized from combining simple, discrete units suggestive of a phrase structure grammar.

Finally, there have been studies on duetting and turn-taking in a variety of primate species. Robinson (1979) described duetting in the territorial calls of titi monkeys, and gibbon song has long been recognized as structured turn taking behavior (e.g., Deputte, 1982). Pygmy marmosets engage in antiphonal calling and do this in predictable sequences (Snowdon \& Cleveland, 1984). Conversational turn taking is an important part of human communication that has many parallels in nonhuman primates.

In summary, from the mid-1970's onward, there had been considerable interest in the cognitive complexity of nonhuman primate vocal communication with several interesting parallels emerging between primate calls and human speech and language (subtle signals varying with context, perceptual categorization of calls, simple grammars, and flexible use of calls depending on context), and these findings have been useful in thinking about the origins of human language.

\section{Context of Referential Communication}

Although the previous primate work provided important insights on primate communication and cognition, what made the vervet monkey (Cercopithecus aethiops, now Choloricebus pygerythrus) alarm call papers so fascinating was not just what they told us about primate cognition, but also because they suggested the possibility that other species could refer to things external to them (as with human words); labeling objects, not just emoting about them. Struhsaker (1967) was the first to describe the alarm calls of vervet monkeys. He described separate calls given to humans, to snakes, to the proximity of a major mammalian or avian predator, to the sudden movement of an avian or mammalian predator and to initial perception of a major avian predator. Thus, there are several more than three calls that vervets give in alarming situations. The genius of Seyfarth et al. (1980a, b) was to select the three most different calls and to test responses to these calls using field playback methods to show that the human classification of the calls was also appropriate for the vervet monkeys. Furthermore, the responses to the calls were functionally appropriate: looking up with an aerial predator call, looking at the ground with a snake alarm call and running into a tree with a mammalian predator alarm call. Although these calls were labeled "eagle", "snake" and "leopard" alarms, Seyfarth et al. (1980b) listed several other potential predators that elicited these alarms. Despite the fact that these calls were not as predator specific as the labels indicated, the broad categorization of avian, snake and mammalian predators still holds.

\section{Predator Alarms in Other Primate Species}

Despite the excitement produced by the vervet monkey research, it has proven difficult to find parallels in many other primate species. Notably, Zuberbühler (2000) found that Diana monkeys 
(Cercopithecus diana) and Campbell's monkeys (Cercopithecus campbelli) have several predator alarm calls and, in areas of sympatry, there is interspecific recognition and response to the calls of the other species. Free ranging ring-tailed (Lemur catta) and ruffed lemurs (Varecia spp.) have separate alarm calls for specific predators and, although ring-tailed lemurs responded to playbacks as predicted by referential signaling (looking up but moving toward cover on the ground with aerial alarms and moving into trees with terrestrial alarms), ruffed lemurs did not (Macedonia, 1990). Predator-specific alarm calls have not been seen in chacma baboons (Papio ursinus; Fischer et al., 2001) with alarm call usage related to urgency rather than predator type. Distinct predator alarms have not been observed in chimpanzees (Pan troglodytes) our closest relatives, though alarms are given selectively depending upon whether social allies are near or not (Crockford et al., 2012).

In New World primates, white-faced capuchin monkeys (Cebus capucinus, now Cebus imitator) have different call types for aerial and terrestrial predators, but the terrestrial calls are not specific to type of predator, and there appears to be considerable gradation, which may be based on response urgency rather than predator type (Digweed et al., 2005; Fichtel et al., 2005). Only two studies of New World primates have shown referential signals. In sympatric saddle-back (Saguinus fuscicollis) and mustached (Saguinus mystax) tamarins, both species have distinct calls to aerial and terrestrial predators and each species responded appropriately to playback of the alarms of their own as well as the sympatric species (Kirchhof \& Hammerschmidt, 2006). Black-fronted titi monkeys (Callicebus nigrifrons) also have predator alarms encoded as probabilistic features in call sequences, and playbacks of these sequences showed appropriate behavioral responses to each call (Cäsar et al., 2012).

\section{Predator Alarms in Non-primate Species}

In the same year as the vervet monkey papers appeared, two other studies showed what appeared to be predator specific alarms in two species of ground squirrels. In both California ground squirrels (Otospermophilus beecheyi, Owings \& Leger, 1980) and Belding's ground squirrels (Urocitellus beldingi, Robinson, 1980) animals had separate alarms for aerial and terrestrial predators, and for California ground squirrels, there was also a separate snake alarm call. Subsequently, similar calls were described in Richardson's ground squirrel (Urocitellus richardsonii, Davis, 1984). These calls led to differential responses: staying alert and scanning the environment in response to a terrestrial alarm call versus taking cover in underground burrows when an aerial predator call was heard.

Why did the ground squirrel papers not attract the same attention as the vervet monkey papers? Perhaps primates generally attract more attention than ground squirrels, but the vervet papers used experimental playbacks of calls whereas the ground squirrel studies were descriptive. Robinson (1980) observed that Belding's ground squirrel alarms were influenced by the amount and type of danger each predator posed and, subsequently, Owings and Hennessey (1984) showed that the calls were associated with threat urgency rather than specific predator type. Thus, an "aerial" alarm was also given when a terrestrial predator was not spotted until close to the burrow entrance, leading to a taking cover response and a "terrestrial" alarm could be given to a hawk that was not in hunting mode, which was followed by increased vigilance. For ground squirrels, a motivational or emotional reaction was a more parsimonious explanation than referential signaling.

Cooperatively-breeding meerkats (Suricata suricatta) also have sentinel alarm calls but these, as with ground squirrels, display variation with respect to response urgency rather than predator specificity. Rarer forms of sentinel calls signaled greater urgency (Rauber \& Manser, 2017) and presence or absence of an audience influenced when and which type of calls would be produced (Townsend et al., 2012). Thus, both urgency and social environment influenced alarm calling more than did reference to a particular predator type. A more detailed analysis of the structure of alarm barks did find a lower first formant frequency in barks given in aerial predator contexts than those given in terrestrial predator contexts (Townsend et al., 2014). Therefore, it is possible that more subtle acoustic analyses might find differences in calls given to different types of predators by other species as well. 
Researchers studying bird behavior had also noticed variation in calling with respect to aerial versus terrestrial predators, but only after the publication of the vervet alarm call paper were similar methods used with birds (see Smith, 2017, for review). Gyger et al. (1987) described distinct aerial and terrestrial alarms in domestic chickens (Gallus domesticus) but observed that these were given to both predators and non-predators, with angular size of an aerial object being more important than predator identity in eliciting calls. Gyger et al. (1986) also found that alarm calls were given only when the caller had other conspecifics nearby. An audience was needed. Evans et al. (1993) recorded alarm calls in cocks in response to simulations of aerial predators and videos of a terrestrial predator and then played back these calls to hens. Playbacks of aerial alarms, led to crouching and looking upwards whereas terrestrial alarm playbacks led hens to adopt an erect, vigilant posture. The authors argued that this demonstrated functional reference of alarm calls in chickens. Subsequent work has shown distinct predator alarms to different predators in Siberian jays (Perisoreus infaustus) and black-capped chickadees (Poecile atricapillus) (c.f., Smith, 2017). Despite intense interest in referential alarm calls, there have been only a few species to show this with many more species exhibiting alarm calling relating more to response urgency or social environment than identifying specific predator types.

\section{Food Calls as Referential Signals}

The vervet monkey alarm calls studies have also led researchers to search for other types of potential referential signaling with food-associated calls being the most commonly studied. Food-related calls have been reported for a variety of avian and mammalian species (see Clay et al., 2012; Smith, 2017; Snowdon, 2010 for reviews). The clearest example of food calls being referential comes from work on chickens. Marler et al. (1986a) showed that chicken responded with greater numbers of calls to more highly preferred foods with few calls to non-food items. Subsequently, the same authors reported that males would give food calls only in the presence of a female and not when alone or with another male present (Marler et al., 1986b), suggesting that food calling may also be part of a courtship strategy. Indeed, Gyger and Marler (1988) showed that, in a semi-naturalistic field situation, cocks gave food calls nearly half the time when no food was present, yet hens approached the callers. Evans and Evans (1999) played back food calls to hens along with ground alarm calls that are similar acoustically, and found that only with food calls did hens exhibit behavior patterns that were part of feeding. Ravens (Corvus corax) produced one type of call when seeing and approaching food and a different call where the rate of calling indexed food quality (Bugnyar et al., 2001). However, other than Benz (1993) working with golden lion tamarins (Leontopithecus rosalia), there is no evidence that there are different food calls for different types of food. It is more common to find that the rate of food calling or the presence or absence of food calls is related to the caller's preference for food or to its divisibility or the degree to which foods can be shared. Thus, the most parsimonious account suggests that food related calls are related to arousal rather than being purely referential (Clay et al., 2012).

\section{Referential Signals Today}

The findings that many predator alarms are also best explained by urgency of the response required coupled with the little evidence of calls specific to food types has led to a debate about whether emotional-motivational factors (Rendall et al., 2009) rather than cognitive-informational factors (Seyfarth et al., 2010) are involved in animal signals. In reality, this is a false dichotomy. Today it is generally accepted that cognitive and emotional components are so intertwined in behavior that it is impossible to attempt to separate them (e.g., Sapolsky, 2017).

An additional critique by Wheeler and Fischer (2012) raises an intriguing idea. They note that giving a fixed call to a fixed stimulus is not very exciting with respect to cognition. They argue that it is more interesting to discover that animals are able to respond to non-specific calls based on social and environmental contexts or to use calls in novel contexts. As examples of this flexibility, captive-born cotton-top tamarins (Saguinus oedipus) do not produce alarms when presented with natural predators such 
as live raptors or snakes (Campbell \& Snowdon, 2009) but they do respond with alarms to veterinarians and cage cleaning equipment. Furthermore, when presented with a familiar, preferred food adulterated with invisible white pepper, the first animals to sample the adulterated foods produced alarm calls (Snowdon \& Boe, 2003). Finally, when calls of natural predators and non-predators were played to captive-born monkeys they responded equally to both types of playback (Friant et al., 2008). Thus, in captivity, tamarins have learned to apply alarm calls to the ecology of captivity and do not respond to natural predators as wild tamarins would. Furthermore, they can apply alarm calls to novel, threatening contexts. This cognitive flexibility is more interesting than a fixed mapping between predator species and call type.

These recent critiques do not detract from the significance of the Seyfarth et al. (1980a, b) papers. The excitement that these two publications aroused has inspired many other scientists to study similar functions in many other species and to look for other potential referential signals. The papers have also stimulated a renewed interest in understanding language origins and have brought attention from birdsong back to potential nonhuman primate models. The papers have also served as a model for field research on communication involving careful documentation of signals and the contexts in which they are observed, followed by ingenious playback studies in the absence of the hypothesized stimulus event. These studies have proven to be a valuable stimulus to animal communication research.

\section{References}

Bauers, K. A., \& Snowdon, C. T. (1990). Discrimination of chirp vocalizations in the cotton-top tamarin. American Journal of Primatology, 21, 53-60.

Benz, J. (1993). Food-elicited vocalizations in golden-lion tamarins: Design features for representational communication. Animal Behaviour, 45, 443-455.

Bugnyar, T. Kijne, M., \& Kotrschal, K. (2001). Food calling in ravens: Are yells referential signals? Animal Behaviour, 61, 949-958.

Campbell, M. W., \& Snowdon, C. T. (2009). Can auditory playback condition predator mobbing in captive reared Saguinus oedipus? International Journal of Primatology, 30, 93-102.

Cäsar, C, Byrne, R. W., Hoppitt, W, Young, R. J., \& Zuberbühler, K. (2012). Evidence for semantic communication in titi monkey alarm calls. Animal Behaviour, 84, 405-411.

Clay, Z, Smith, C. I., \& Blumstein, D. T. (2012). Food-associated vocalizations in mammals and birds: What do these calls really mean? Animal Behaviour, 83, 323-330.

Cleveland, J., \& Snowdon, C. T. (1982). The complex vocal repertoire of the adult cotton-top tamarin (Saguinus oedipus). Zeitschrift für Tierpsychologie, 58, 231-270

Crockford, C., Wittig, R., Mundry R., \& Zuberbühler, K. (2012). Wild chimpanzees inform ignorant group members of danger. Current Biology, 22, 142-146.

Davis, L. S. (1984). Alarm calls in Richardson's ground squirrels. Zeitschrift für Tierpsychologie, 66, 152-164.

de la Torre, S., \& Snowdon, C. T. (2002). Environmental correlates of vocal communication of wild pygmy marmosets, Cebuella pygmaea. Animal Behaviour, 63, 847-856.

Deputte, B. L. (1982). Duetting in male and female songs of white-cheeked gibbons (Hylobates concolor leucogenys). In. C. T. Snowdon, C. H. Brown, \& M. R. Petersen (Eds.), Primate communication (pp. 6793). Cambridge University Press.

Digweed, S., Fedigan, L., \& Rendall, D. (2005). Variable specificity in the anti-predator vocalizations and behaviour of white-faced capuchin monkeys (Cebus capucinus). Behaviour, 142, 997-1021.

Evans, C. S., \& Evans, L. (1999). Chicken food calls are functionally referential. Animal Behaviour, 58, 307-319.

Evans, C. S., Evans, L., \& Marler, P. (1993). On the meaning of alarm calls: Functional reference in an avian vocal system. Animal Behaviour, 46, 23-48.

Fichtel, C., Perry, S., \& Gros-Louis, J. (2005). Alarm calls of white-faced capuchin monkeys: An acoustic analysis. Animal Behaviour, 70, 165-170.

Fischer, J., Hammerschmidt, K., Cheney, D. L, \& Seyfarth, R. M. (2001). Acoustic features of female chacma baboon barks. Ethology, 107, 262-275.

Friant, S. C., Campbell, M. W., \& Snowdon, C. T. (2008). Captive-born cotton-top tamarins (Saguinus oedipus) respond similarly to predators and sympatric non-predators. American Journal of Primatology, 70, 707710. 
Green, S. (1975). Variation in vocal patterns with social situation in the Japanese monkey (Macaca fuscata). A field study. In L. A. Rosenblum (Ed.), Primate behavior, Vol 4 (pp. 1-102). Academic Press.

Griffin, D. R. (1976). The question of animal awareness. Rockefeller University Press.

Gyger, M., Karakashian, S. J., \& Marler, P. (1986). Avian alarm calling: Is there an audience effect? Animal Behaviour, 34, 1570-1572.

Gyger, M., Marler P., \& Pickert, R. (1987). Semantics of an avian alarm calls system: The male domestic fowl, Gallus domesticus. Behaviour, 102, 15-40.

Gyger, M., \& Marler, P. (1988). Food calling in the domestic fowl, Gallus gallus: The role of external referents and deception. Animal Behaviour, 36, 358-365.

Kirchhof, J., \& Hammerschmidt, K. (2006). Functionally referential alarm calls in tamarins (Saguinus fuscicollis and Saguinus mystax) - Evidence from playback experiments. Ethology, 112, 346-354.

Lillehei, R. A., \& Snowdon, C. T. (1978). Individual and situational differences in the vocalizations of young stumptrail macaques (Macaca arctoides). Behaviour, 65, 270-281.

Macedonia, J. M. (1990). What is communicated in the antipredator calls in lemurs: Evidence from playback experiments with ringtailed and ruffed lemurs. Ethology, 86, 177-190.

Marler, P., Dufty, A., \& Pickert, R. (1986a). Vocal communication in the domestic chicken. I. Does the sender communicate information about the quality of a food referent to a receiver? Animal Behaviour, 34, 188193.

Marler, P., Dufty, A., \& Pickert, R. (1986b). Vocal communication in the domestic chicken: Is a sender sensitive to the presence and nature of the receiver? Animal Behaviour, 34, 194-198.

May, B. B., Moody, D. B., \& Stebbins, W. C. (1989). Categorical perception of conspecific communication sounds by Japanese macaques, Journal of the Acoustical Society of America, 85, 837-847.

Miller, C. T., Flusberg, S., \& Hauser, M. D. (2003). Interruptibility of long call production in tamarins: Implications for vocal control. Journal of Experimental Biology, 206, 2629-2639.

Moynihan, M. (1970). The control, suppression, decay, disappearance, and replacement of displays. Journal of Theoretical Biology, 29, 85-112.

Neisser, U. (1967). Cognitive psychology. Appleton Century.

Owings, D. H., \& Hennessey, D. F. (1984). The importance of variation in sciurid visual and vocal communication. In J. O. Murie, \& G. L. Michener (Eds.), The biology of ground dwelling squirrels. (pp. 169-200). University of Nebraska Press.

Owings, D. H., \& Leger, D. W. (1980). Chatter vocalizations in California ground squirrels: Predator and social role specificity. Zeitschrift für Tierpsychologie, 54, 163-184.

Petersen, M. R., Beecher, M. D., Zoloth, S. T., Green, S., Marler, P., Moody, D. B., \& Stebbins, W. C. (1984). Neural lateralization of vocalizations by Japanese macaques: Communicative significance is more important than acoustic structure. Behavioral Neuroscience. 98, 779-790.

Pola, Y. V., \& Snowdon, C. T. (1975). The vocalizations of pygmy marmosets (Cebuella pygmaea). Animal Behaviour, 23, 826-842.

Rauber, R., \& Manser, M. B. (2017). Discrete call types referring to predation risk enhance the efficiency of the meerkat sentinel system. Scientific Reports, 7, 44436.

Rendall, D., Owren, M. J., \& Ryan, M. J. (2009). What do animal signals mean? Animal Behaviour, 78, 233-240.

Robinson, J. G. (1979). An analysis of the vocal communication in the titi monkey, Callicebus moloch. Zeitschrift fur Tierpsychologie, 49, 381-405.

Robinson, S. R. (1980). Anti-predator behavior and predator recognition in Belding's ground squirrels. Animal Behavior, 28, 840-852.

Sapolsky, R. M. (2017). Behave: The biology of humans at our best and worst. New York: Penguin Press.

Seyfarth, R. M., Cheney, D. L., \& Marler, P. (1980a). Monkey responses to three different alarm calls: Classification and semantic communication. Science, 210, 801-803.

Seyfarth, R. M., Cheney, D. L., \& Marler, P. (1980b). Vervet monkey alarm calls: Semantic communication in a free-ranging primate. Animal Behaviour, 28, 1070-1094.

Seyfarth, R. M., Cheney, D. L., Bergman, T., Fischer, J., Zuberbühler, K., \& Hammerschmidt, K. (2010). The central importance of information in studies of animal communication. Animal Behaviour, 80, 3-8.

Smith, C. I. (2017). Referential signaling in birds: The past, present and future. Animal Behaviour, 124, 315-323.

Smith, W. J. (1969). Messages of vertebrate communication. Science, 165, 145-150.

Snowdon, C. T. (2010). Food signals. In M. Breed \& J. Moore (Eds.), Encyclopedia of animal behavior (pp. 744748). Elsevier. 
Snowdon, C. T., \& Boe, C. Y. (2003). Social communication about unpalatable foods in tamarins (Saguinus oedipus). Journal of Comparative Psychology, 117, 142-148.

Snowdon, C. T., \& Cleveland, J. (1984). "Conversations" among pygmy marmosets. American Journal of Primatology, 7, 15-20.

Snowdon, C. T., \& Hodun, A. (1981). Acoustic adaptations in pygmy marmoset contact calls: Locational cues vary with distance between conspecifics. Behavioral Ecology and Sociobiology, 9, 295-300.

Snowdon, C. T., \& Pola, Y. V. (1978). Interspecific and intraspecific responses to synthesized pygmy marmoset vocalizations. Animal Behaviour, 26, 192-206.

Struhsaker, T. T. (1967). Auditory communication among vervet monkey (Cercopithecus aethiops). In S. A. Altmann (Ed.), Social communication among primates (pp. 281-324). Chicago University Press.

Townsend, S. W., Charlton, B. D., \& Manser, M. (2014). Acoustic cues to identity and predator context in meerkat barks. Animal Behaviour, 94, 143-149.

Townsend, S. W., Rasmussen, M., Clutton-Brock, T., \& Manser, M. B. (2012). Flexible alarm calling in meerkats: The role of the social environment and predation urgency. Behavioral Ecology, 23, 1360-1364.

Wheeler, B. C., \& Fischer, J. (2012). Functionally referential signals: A promising paradigm whose time has passed. Evolutionary Anthropology, 21, 195-205

Zoloth, S. R., Petersen, M. R., Beecher, M. D., Green, S., Marler, P., Moody, D. B., \& Stebbins, W. C. (1979). Species-specific perceptual processing of vocal sounds by monkeys. Science, 204, 870-872.

Zuberbühler, K. (2000). Interspecific semantic communication in two forest monkeys. Proceedings of the Royal Society of London, B, 267, 713-718. 